\title{
Olinda: Um Novo Estilo de Govêrno
}

\author{
(Integração dos Valores da Comunidade na Administração \\ do Municipio)
}

\section{Barreto Guimarães}

Inúmeros trabalhos dignos de análise e meditação têm sido divulgados pela Revista do Serviço Público, no que se refere aos problımas do govêrno e administração municipal. Aliás, desde sua fundação que a Revista do Serviço Público dedica uma Seção especial aos Municipios, divulgando trabalhos rigorosamente selecionados a respeito das necessidades, reivindicaçõzs e assuntos vinculados às Comunas brasileiras. Prefeitos, Vereadores, Autoridades e Técnicos interessados na solução dos mencionados problemas acompanham, com justificada curiosidade, as iniciativas editoriais do Serviço de Documentação do D.A.S.P. - através da Revista do Serviço Público - tendo em vista a emancipação global e o desenvolvimento planificado das Unidades Elementares da Federação. $\mathrm{Na}$ presente edição, a Revista do Serviço Público chama a atenção dos seus leitores para a Tese do ilustrte Prefeito Barreto Guimarães: "Olinda - Um novo estilo de Govêrno" (Integração dos Valores da Comunidade na Administração do Municipio). Trata-se de uma contribuição de mérito incontestável que o $V$ Congresso Nacional dos Municipios recentemente encerrado na cidade do Recife, a 8 de dezembro de 1959 - aprovou, por unanimidade. Êsse trabalho do Prefeito Barreto Guimarães, depois de exaustivamente debatido nas Comissões Técnicas e no Plenário do aludido Congresso, mereceu a honra de uma Recomendação Especial, no sentido de ser. encaminhado a tôdas as Prefeituras e Câmaras Municipais do Brasil em virtude das sugestões que nêle se consubstanciam relativamente à implantação, em tôdas as Comunas, dos "Conselhos Municipais de Desenvolvimento". A Revista do Serviço Público, atendendo a essa Recomendação Especial do Congresso do Recife, publica a magnífica Tese do Prefeito Barreto Guimarães, conscia de que está prestando mais um valioso serviço aos Municipios Brasileiros. - (Nota da Redação). 
TESE APRESENTADA PELO SR. BARRETO GUIMARÃES, PREFEITO DE OLINDA, AO V CONGRESSO NACIONAL DE MUNICÍPIOS

$\mathrm{R}$

Fpassando os anais da Assembléia Constituinte de Pernambuco, exatan mente na resenha dos trabalhos de uma reunião realizada a 16 de maio de 1935, verificamos o entusiasmo com que sabia defender as teses municipalistas, o saudoso professor e homem público que foi Andrade Bezerra.

Chegara mesmo a afirmar que, em Sociologia Prática e em Direito Público não há problema mais interessante, a reclamar a atenção de juristas e sociólogos, do que o problema do municipalismo, ou para denominá-lo em têrmos mais simples, da restauração da vida local.

Um político espanhol - Maura - justificando um projeto de reforma municipal. salientava que "são motivos de coexistência geográfica, interêsses comuns de vizinhança e inclinações de sociabilidade natural que vão formando os municípios. Na vida local está a iniciação da cidadania, por que o amor da adolescência é a pequena pátria".

Poderíamos, até, recorrer à evocação de Tocqueville, no vibrante interêsse pelas franquias locais dos anglo-saxônicos, quando declarava que "o municipin existe em todos os povos, quaisquer que sejam as suas leis e costumes. Organiza e forma tanto os reinos como as repúblicas. $\mathrm{O}$ município parece que saiu das mãos de Deus. É a primeira escola onde o cidadão deve aprender os seus deveres politicos e sociais."

Vê-se com êsses poucos, mas expressivos, exemplos que é indiscutivel a importância do município na formação das nacionalidades. $O$ primeiro amor cívico, nasce realmente, nos municípios. E, se adotamos o conceito de Joaytim Nabuco que nos informa ser o traço todo da vida o desenho da crianca esquecido pelo homem, mas ao qual êle trá sempre que se cingir. sem o saber, então, constataremos o quanto são poderosas as influências do Município, sôbre cada um de nós e como são fortes os vínculos que nos ligam à vida dos municípios. Pois é no município que nós passamos a nossa infância, vivemos a adolescência e a juventude.

Araújo Cavalcanti, um dos municipalistas mais convictos e brilhantes que conhecemos, soube definir, muito bem, a posição do legislador constituinte com relação à importância do Municipalismo, quando, em seu trabalho intitulado "Desenvolvimento Econômico e Social dos Municípios", afirmou que os dispositivos constitucionais configuram, embora sumàriamente, os fatôres que fazem das comunas os núcleos vitais da estrutura da Federação brasileira, integrada na hierarquia natural das três órbitas e indivisivel na sincronia dos interêsses federais, regionais ou locais.

Todos os pronunciamentos dos estudiosos do municipalismo, ressaltam a significação do Município na vida de uma Nação. Entendemos que algumas reformas precisam ser feitas no texto da nossa Carta Magna e também nas Constituições dos Estados, para que o municipalismo possa sair do plano da doutrina para a área da ação objetiva, prática e realizadora.

Alguns direitos do Município estão postergados pela União e pelo Estado e o caminho seguro que nos conduzirá à correção dessa anomalia é, realmente, a alteração dos textos constitucionais. Sempre definimos como 
perigosas as reformas da Constituição. Mas a Carta Magna não é, nem poderia ser, imutável. Razões de ordem politica, social ou econômica, justificam as alterações dêsses documentos legais.

O nosso modesto trabalho, entretanto, tem por objetivo oferecer uma diretriz aos governos municipais, para que possamos resolver alguns aspectos de determinados problemas e mesmo alguns problemas municipais, com os recursos próprios de cada comunidade.

No propósito de encaminhar o desenvolvimento desta tese pela senda do objetivismo, tornando a sua apresentação caracteristicamente prática, apresentaxemos o exemplo das medidas que adotamos no Municipio de Olinda.

Logo as urnas do último pleito municipal anunciaram a nossa vitória, começamos a tomar providências indispensáveis à execução de um plano administrativo. Verificamos que precisávamos da participação do técnico no Govêrno Municipal. Pois, não seria possivel realizar uma obra administrativa sem a participação dos técnicos. Mas, como fazê-lo, se os recursos firanceiros da Prefeitura de Olinda não permitem que um técnico tenha remuneracão superior aos vencimentos de um contínuo de repartição pública federal? Estava, assim, afastada a hipótese da participação do técnico na administração municipal, em têrmos de remuneração. Mas não podia prescindir da sua colaboração.

Tomamos, então, a iniciativa de organizar comissões de planejamento, iniegradas pelos técnicos locais. Nada menos de sete comissões, foram criadas, para o planejamento, em bases orgânicas, científicas, racionais e técnicas, de todos os setores de administração pública do Município de Olında. Era o primeiro esfôrço no sentido de evitar um trabalho dispersivo, desordenado e empírico. Planejamento visa o melhor e o maior aproveitamento dos recursos aplicados e dos esforços dispendidos. Planejamento é a disciplina para a ação ordenada.

Criamos, assim, a Comissão de Planejamento Urbanístico, constituída de engenheiros e arquitetos e cujo objetivo principal é a elaboração de um Plano Diretor da cidade de Olinda, a fim de evitar o seu crescimento desordenado. Certo que essa Comissão terá de encarar uma gama de problemas com os seus múltiplos aspectos. Até por que o urbanismo tem como centro de gravitação o próprio homem. Assim, tôdas as indigências do homem, na sua vida em sociedade, são apreciadas pelo Urbanismo. Problemas de economia, transporte, escoamento, educação, saúde, abastecimento, água. esgotos, luz, enfim, todos os problemas da comunidade, incluindo, atè, os logradouros públicos, os "play-grounds" para crianças, os jardins para velhos, as áreas comerciais e industriais, o fomento à produção de qualquer ordem, os desportos, os centros de recreação, são analisados por uma comissão que se destina a traçar um plano de urbanização para uma cidade.

A Comissão de Saúde formada por médicos, dentistas, enfermeiros, higienistas, sanitaristas e especialistas dos diversos ramos e setores da medicina.

A Comissão de Educação é outra que compõe o sistema das Comissões de Planejamento, como de resto, as de Turismo, Transportes, Abastecimentos e elaboradora do Código Tributário. 
Duas razões nos levaram à criação dessas Comissões:

$\left.1^{a}\right)$ a necessidade de um planejamento técnico em todos os setores da administração; e

$\left.2^{a}\right)$ a necessidade de integração de todos os valores técnicos e de tôdas as camadas sociais no Govêrno do Município.

A constituição dêsses órgãos nos revelou a riqueza de valores humanos da comunidade olidense. Médicos, dentistas, advogados, economistas, estudiosos dos problemas sociais, professôres, engenheiros, arquitetos, contabilistas, agrônomos, químicos, todos integrados, de agora em diante, no esfôrço comum de desenvolvimento do Municipio de Olinda.

Antes êles existiam como simples moradores da cidade. Eram fôrças latentes que não tinham, ainda, sido usadas em defesa da comunidade, através da colaboração direta com a administração pública. Hoje, são expressões dinâmicas, valores absolutamente integrados na luta tenaz e difícil, pelo progressu da sua comuna, fatôres positivos do Govêrno Municipal. Melhor identificados com os problemas locais, contribuindo para a sua solução definitivąa e, o que é mais importante, consolidando a sua consciência municipalista. Pois, o municipalismo é dinamismo, é esfôrço constante pela fixação do hrmem à sua gleba, é luta pelo progresso das comunas e pela sua independência de tôda ordem. É um movimento da emancipação que exige a participaçâo de todos. E só com uma tomada de consciência do problema, seria possivel conduzir o povo para a batalha municipalista.

Distribuídos êsses valores nas diversas comissões técnicas o que nos restava era tornar possivel a integração das chamadas massas populares no Gcvêrno Municipal. Para isto, adotamos o chamado Gabinete de Campo de Prefeito de Olinda: uma barraca de lona, desmontável, com mesa rústica e bancos simples, instalada nas zonas pobres da cidade para que o Govêrno chegue até o povo. Foi a substituição da frase demagógica e já transfortnada em lugar comum - as portas do Palácio estão abertas para o povo por uma realidade incontestável. consubstanciada na presença do governante junto às populações desajustadas e infelizes.

Nessa barraca - verdadeiro gabinete portátil - instalada periòdicamente em cada zona pobre da cidade, fazemos reuniões com os nossos auxilidres imediatos, sob as vistas da população local que dela se aproxima. ouvindo, dessa forma, os debates que travamos sôbre os problemas de interêsse geral sôbre os que digam respeito àquela determinada localidade.

Depois dessas reuniões com os diretores, saimos para verificar "in-loco" as necessidades do bairro ou distrito e, em seguida, realizamos uma audiência pública.

O Prefeito deixa de ser uma figura mitológica, inabordável, inaccessivel, para se transformar num homem comum, com quem se fala, de quem se discorla e com quem se debate as necessidades locais. O povo se integra, for êsse processo, na administração do municipio. 
Tôdas as camadas sociais estão, assim, ligadas ao Govêrno, participando dêle, sentindo-se também Govêrno, o que é altamente democrático.

Mas essas comissões de planejamento que funcionam sem ônus para a Prefeitura, deixarão de existir quando terminarem a sua tarefa específica, organizarem os seus planos. Têm vida curta, como se vê. Era preciso, então, que se criasse um órgão, sob inspiração dos mesmos propósitos e fundamentados nas mesmas causas e nos mesmos critérios que nos levaram à criação das comissões de planejamentos, mas de vida permanente, para substituir as referidas comissões. Órgão consultivo. formado, também, por engerheiros, urbanistas, arquitetos, professôres, advogados, médicos, dentistas economistas, sociólogos, contabilistas. farmacêuticos, agrônomos, químicos, funcionários públicos, operários, estudantes e representantes do Clero, das Fèrça- Armadas, da indústria e do comércio, da oposição e do govêrno na Câmnra Municipal. Esse órgão será o Conselho de Desenvolvimento do Municipio de Olinda, que funcionará, permanentemente, como órgão consultivo e sob a presidência do Vice-Prefeito do Município, o advogado Benjamim de Aguiar Machado.

Com essa base e sôbre êsses alicerces, poderemos realizar um govêrno com as seguintes diretrizes:

a) integração de todos os valores técnicos na administração;

b) integração de tôdas as camadas sociais no Govêrno do Município;

c) aplicação racional e com a maior rentabilidade possivel dos poucos recursos financeiros da Prefeitura;

bem comum;

d) dinamização de todos os valores da comunidade no sentido do

e) orientação democrática do govêrno com a participação de todos, sem a exclusão de nenhum; $e$

f) formação de uma consciência-municipalista.

\section{CONCLUSÃO}

O que sugerimos, então, é o seguinte:

1.) Criação em todos os municipios do Brasil, dessas Comissões de Planejamento, de acôrdo com as possibilidades de cada um dêles, para que o plano de govêrno seja apoiado em bases técnicas, orgânicas, racionais e ciennifi:cas. fugindo ao empirismo e à dispersão decorrente da improvisação e pa'a que se torne uma realidade a integração de todos os valores humanos da eumunidade do Govêrno do Município.

2:) Criação, em todos os municipios do Brasil, de um órgão consultivo, forma do na obediência ao mesmo critério e sob inspiração das mesmas causas que orientaram a formação das Comissões de Planejamento. Se as Comissỏes de Planejamento têm vida curta, êsse órgão tem caráter de permanência e deve chamar-se Conselho Municipal de Desenvolvimento.

Olinda, novembro de 1959. - Barreto Guimarães, Prefeito de Olinda. 


\section{DISCURSO DE POSSE}

Sr. Presidente da Câmara de Vereadores de Olinda

Srs. Vereadores

Autor:dades

Senhoras e senhores.

Participando dêste ato solene e sendo empossado no cargo de Prefeito do Município de Olinda perante esta Câmara Municipal, não o faço, apenas, com o entusiasmo de um democrata que cumpre um dispositivo da nossa Constituição. Nem interpreto esta solenidade pelo formalismo de que ela pessa se revestir. Estou aqui, também, impelido pela vontade de prestar hemenagem que considero das mais justas a todos os senhores vereadores que integram esta Câmara. Oposicionistas ou governistas, na realidade, eles são minhas senhoras e meus senhores, os detentores de mandatos populares conquistados legítima e democràticamente, depois de uma campanha politica, às vêzes caracterizada pela aspereza das investidas e nem sempre à altura do melhor estilo pernambucano e da tradicional fidalguia dos olidenses, mas, em última análise, reveladora da maturidade política do nosso pov̀o.

Preciso dizer aos vereadores olidenses, que tenho sido, em muitas oportunıdades, um ardoroso defensor desta Casa, contra muitas acusações que lhe são feitas, por quem, naturalmente, desconhecendo a autenticidade dos vossos mandatos, procura anular o vosso espírito público e negar o idealismo das vossas deliberações. E esta minha atitude não exige retribuição. Pois é ditada pela observação que venho fazendo do vosso empenho em defesa do interêsse coletivo e inspirada no mais alto sentimento de justiça. Estou certo, portanto, de que estamos orientados para o mesmo sentido. Temos uma tarefa comum a realizar: a grandiosa tarefa do soerguimento e do progresso de Olinda.

Conheceis, como eu, os problemas e as imensas dificuldades que nos esperam. Vamos governar uma cidade cuja população ultrapassou de 100 mil habitantes, com uma receita de 50 milhões de cruzeiros, quase tôda ela comprometida com pagamento de pessoal. E nem por isto, os operários, as professôras e o funcionalismo têm recebido, em dia, os seus salários e venciraentos. Aqui, quando o obituário geral atinge a 82 pessoas, vamos encontrar 50 crianças entre 0 e 1 ano. Um indice de mortalidade infantil, portanto, sòmente comparável aos das regiões mais subdesenvolvidas do mundo. Vamus governar uma cidade em que, no capítulo da educação, um exemplo, apenas. seria bastante para traduzir a indigência em que vive o nosso povo. Além de um apavorante indice de analfabetismo, presenciamos, todos os anoz, ao desolador espetáculo de milhares de crianças voltando para as suas casas, sob os olhares de frustração dos seus pais, porque não conseguem matriculas nas escolas públicas e nas obras sociais. O mínimo de confôrto que deve ser possibilitado a uma população, por um bom serviço de abastecimento d'água, não chega às casas dos olidenses. A distribuição de energia elétrica é precária e êste serviço industrializado da Prefeitura, é dos mais deficitários. Situada tão próxima à capital pernambucana, Olinda ainda 
não recebeu os benefícios do saneamento, com instalação de esgotos. Não temos mercado de trabalho em correspondência com o mínimo das necessidacies da nossa população. Vamos governar uma cidade em que nos morros, córregos, alagados e praias distantes, constatamos a presença de uma populaçào superior a 60.000 habitantes, quase tôda ela atingida pelas mais diversas formas de servidão humana.

A minha primeira identificação com êste povo pobre de Olinda, data de miitos anos, quando, sentindo a miséria da fome, do desemprêgo, da ignorância e da doença, presente à vida nos mocambos, parti para uma arrancada atrevida e cheia de ousadia - como tôda ação estimulada pelo idealismo dos jovens - consubstanciada numa obra social - sintese de uma tertativa de educação popular - que ainda hoje, atenua o drama dessas populações desajustadas. Posso, assim, falar-vos com a autoridade que me é conferida pela experiência dessa atividade social, sôbre, já não sei se poderia dizer a vida ou melhor diria, a sobrevivência dessa gente pobre da nossa terra.

Se a alguém não comover o sofrimento dêsses milhares de brasileiros, haver.́., sem dúvida, de tocar à sua sensibilidade o estoicismo e sobretudo a resignação de todos êles. É tudo assim, grotesco e impressionante no seut aspecto, às vêzes dramático. E' tudo, assim, reclamando dos administradores públicos firmeza, coragem e ânimo forte, para que alguma coisa seja feita diante do quase tudo que está por fazer. Mas, com a compreensão do povo e o nosso entendimento, haveremos de realizar um trabalho que possa ser a demonstração do nosso espírito público e a revelação do nosso inabalével propósito de servir à coletividade olidense.

O dever que me impõe a condição de chefe do Govêrno Municipal de Olinda, animado pelo sentimento de solidariedade humana e pelo patriotismo. fatôses que haverei de ter sempre presentes no exercício do meu mandato, reclamam de mim uma atenção especial para os problemas dessas inferiores camadas sociais. Essa minha decisão é irreversivel. Dêsse roteiro ninguém me afastará.

Não posso, entretanto, esquecer ou desprezar aquelas providências admiristrativas que, ligadas aos fatôres de progresso e desenvolvimento do municipio, serão as veredas por onde canalizaremos os recursos financeiros inclispensáveis à execução de obras públicas que visem o bem-estar social.

Srs. Vereadores - Somos, na verdade, dois Podêres autônomos, independentes e harmoniosos entre si. Mas quase nada poderia fazer sem a vossa indispensável colaboração, sem o permanente apoio desta Casa. Confio em que êste apoio não me faltará nunca. E. assim, poderemos juntos e com a solidariedade do povo, sair vitoriosos dessa luta que estamos iniciando agora. Luta árdua, tenaz e difícil, mas cujos fins, que não são outros senão o progresso de Olinda e a felicidade do povo, representarão o maior estimulo para que nela permaneçamos e a causa do otimismo que será a ccnstante das nossas atividades.

Vamos traçar novos rumos para a nossa terra comum. Vamos planejar. parł a ação. Vamos trabalhar para que não sejam traídas ou negadas as tradições desta velha e histórica cidade de Olinda. Vamos lutar por um 
povn que confia em nós e que muito espera da nossa capacidade de realização.

Quero, agora, declarar que não conheço e nem poderia conhecer o limite da minha vida pública. Mas, qualquer que êle venha a ser, não creio na existência de muitos títulos que possa conquistar e que se nivelem à posição honrosa e à importância histórica do título de Prefeito de Olinda e do galardâo da confiança dos olidenses.

Berço da nacionalidade brasileira, através de embates os mais renhidos. em cite os nossos antepassados revelaram o seu heroismo e a sua inexcedivel pugnacidade. Teatro das lutas mais belas e dignificantes em defesa das libcrdades, quando os antigos escreveram, aqui, nestas colinas seculares e nestes sitios históricos, as mais admiráveis páginas da nossa emancipação política e cultural. Sede de instalação dos Cursos Jurídicos e dos mais notáveis movimentos culturais do Brasil. Pioneira dos anseios republicanos dos Lrasileiros e até das cruzadas abolicionistas, Olinda ainda tem nas suas igrejas vetustas, nos conventos, nas ruinas dos fortes, no casario antigo, os simbolos da sua proeminência na formação da História do Brasil. Aqui estãc as matrizes da nacionalidade brasileira. Podeis. então, aquilatar o meu entusiasmo ao ser empossado no cargo de Prefeito de todos os olidenses.

Srs. Vereadores - ao partirmos para esta peleja em defesa do nosso pnvo e desta querida cidade de Olinda, volvamos o pensamento para os destinos da nossa Pátria. A desarticulação dos partidos políticos que estão desacreditados perante a opinião pública, quando sabemos que êles são o sustestáculo da Democracia. A crise de liderança política dando origem aus ismandos carismáticos. A crise moral que impede, aqui e ali, a honesta aplic:ição do dinheiro do povo. Tôdas essas fendas abertas na estrutura politica, social e financeira do Brasil, estão a reclamar de todos nós um esfôres de tôdas as horas e uma luta de todos os instantes, para, sob inspiraçán rea'mente patriótica, oferecermos com exemplos de renúncia e desprendimento, a nossa contribuição para o fortalecimento da democracia brasileira.

Que Deus nos ajude a defender o Brasil e Pernambuco e a lutar, sem desfalecimentos pela grandeza de Olinda'e pela felicidade do seu povo. 